\title{
Supramolecular assembly of $p$-tert-butylthiacalix [6] arene with benzylamine complex based on hydrogen bond
}

\author{
Yoshihiko KONDO and Fumio HAMADA* \\ *Department of Materials-Process Engineering and Applied Chemistry for Environments, Faculty of \\ Engineering and Resource Science, Akita University, Tegata, Akita, 010-8502, Japan \\ E-mail :hamada@ipc.akita-u.ac.jp
}

\begin{abstract}
It is well known that $p$-tert-butylthiacalixarenes can make host-guest complexation with organic guest molecules and metal cations. In order to study crystal structural properties of the host molecule with organic compounds, we tried to make a new crystal of the p-tert-butylthiacalix[6] arene with benzylamine. Treatment of thiacalix [6] arene with excess of benzylamine afforded the complex of thiacalix $[6]$ arene with 8 molecules of benzylamine as crystals, which shows highly-extensive hydrogen bonded between host and guests to give rise to supramolecular assembly. The structure of thiacalix [6] arene as a host is 1,2,3-alternate with 4 molecules benzylamine as inner guests and the other 4 molecules of benzylamine locate outside of thiacalix $[6]$ arene.
\end{abstract}

Key Words : thiacalixarene, crystal structure, hydrogen bonding, supramolecular assembly

\section{Introduction}

Thiacalixarenes, which has sulfur atoms in place of $\mathrm{CH}_{2}$ bridges of calixarenes, have been attracted considerable interest in the supramoplecular chemistry. The sulfur and phenol groups in the thiacalixarenes can coordinate with metal ions, which produce supramolecular assembly [1,2]. Recently, we reported the potassium complexes of thiacalix $[n]$ arenes $(n=6$ and 8$)$, which show highly-extensive coordination that give rise to zeolitic structure $[3,4]$. On the other hand, the crystal structures of thiacalix $[6]$ arene with organic guest molecules such as dichloromethane have been reported by a couple of groups [5]. The crystal structure of aromatic guest such as toluene and benzyl alcohol with thiacalix $[6]$ arene have been reported by us, which is the first example that the aromatic guest was employed [6]. In the system of the complex of benzyl alcohol with thiacalix [6] arene, intermolecular hydrogen-bond was recognized between host and guest. The formation of hydrogen bonds as well as metal coordination bonds is one of the major driving forces in supramolecular chemistry. As a consequence, interest in the investigation of hydrogen-bonded systems is still growing [7]. In the crystalline structure of thiacalix $[6]$ arene with benzylamine, the existence of hydrogen bond was found between four host-guest interactions, three host-guest-guest-guest-host interactions and one host-guest-host interaction, which resulted in the formation of supramolecular assembly. There are a couple of examples that have shown such an intermolecular hydrogen bonds in substituted calixarenes [8]. However, there is few examples of the intermolecular hydrogen bonds that have been shown in native calixarenes and thiacalixarenes.

\section{Experimental}

\section{X-Ray crystallography}

Treatment of thiacalix [6] arene with excess of benzylamine afforded crystals after a period of two days and their X-ray structure was determined. Crystal data for p-tert-butylthiacalix [6] arene with benzylamine: $\mathrm{C}_{116} \mathrm{H}_{144} \mathrm{~N}_{8} \mathrm{O}_{6} \mathrm{~S}_{6}, \quad \mathrm{M}=1938.82$, colorless, crystal dimensions $0.40 \times 0.30 \mathrm{x} 0.30 \mathrm{~mm}$, triclinic, space group P-1 (No.2), $a=14.3293(3), b=16.4888$ (1), $c=26.1091$ (4) $\quad \AA, \quad \alpha=75.615(1), \quad \beta=80.2105(7), \quad \gamma=$ $66.7894(9) \mathrm{deg}, \quad V=5438.8(2) \AA^{3}, \mathrm{Z}=2 .$, Mo-K $\alpha$ radiation $(\lambda=0.7107 \AA), \quad \rho_{\text {calc }}=1.176 \mathrm{~g} \mathrm{~cm}^{-3}, \mathrm{~T}=93.23 \mathrm{~K}$, numerical absorption correction, $\mu(\mathrm{Mo}-\mathrm{K} \alpha)=0.181 \mathrm{~cm}^{-1}$, transmission 0.738-0.922, data collections using Rigaku RAXIS-RAPID imaging plate diffractometer, 42480 measured reflections, 22704 unique reflections $\left(R_{\text {int }}=0.0803\right), 16829$ observed reflections $(I>3.00 \sigma(\mathrm{I})), 1323$ parameters, $\mathrm{R}=0.044, w \mathrm{R}=0.2043$, refined against $|\mathrm{F}|, \mathrm{GOF}=1.707$. CCDC 268308. Copies of the data can be obtained free of charge on application to CCDC, 12 Union Road Cambridge CB2, 1EZ, UK (fax : $(+44) 1223-336-033$; e-mail: deposit@ccdc.cam.ac.uk).

\section{Result and discussion}

It is reported that calix $[6]$ arenes are more flexible than calix [4] arenes and crystal structure determination shows that the cone conformation is lost. Two classes have been described; one has a conformation with symmetry planes, the other a centro symmetric conformation[9]. In principle thiacalix [4] arenes is cone conformation, although there are few examples of conformation data of $p$-tert-butylthiacalix [6] arene. Only a data of solid-state conformation with dichloromethane as a guest shows 
that $p$-tert-butylthiacalix $[6]$ arene adopts a distorted cone conformation[10]. As shown in Figure 1, the structure of thiacalix $[6]$ arene with benzylamine is 1,2,3-alternate structure which is similar to that of potassium complex of thiacalix [6] arene reported previously[3]. A detailed inspection of the intermolecular hydrogen bonded pattern of the structure reveals an intricate network of interactions that provide a high degree of stability to the lattice. Each thiacalix [6] arene binds 8 molecules of benzylamine, in which 4 molecules of benzylamine are included in the cavity of thiacalix $[6]$ arene and the other 4 benzylamine are located at interlayer of thiacalix $[6]$ arene. Four benzylamine molecules are included in the cavity of thiacalix [6] arene, in which benzylamine (a) interacts with thiacalix [6] arene and neighboring benzylamine molecules (b) through with intermolecular $\mathrm{NH}^{\cdots} \cdot \mathrm{S}$ and $\mathrm{NH} \cdots \mathrm{N}$ with a distance of 3.539 $\AA$ and $2.957 \AA$, respectively, neighboring benzylamine (b) was bound as well with 2 sets of $\mathrm{NH} \cdots \mathrm{O}$ and $\mathrm{N} \cdots \mathrm{OH}$ with a distance of $2.874 \AA$ and $2.660 \AA$, respectively. The other two of benzylamine ( $\mathrm{c}$ and $\mathrm{d}$ ) bond with intermolecular $\mathrm{NH} \cdots \mathrm{S}$ and $\mathrm{N}$ $\mathrm{H} \cdots \mathrm{O}$ with $3.490 \AA$ and $3.161 \AA$, respectively and the other

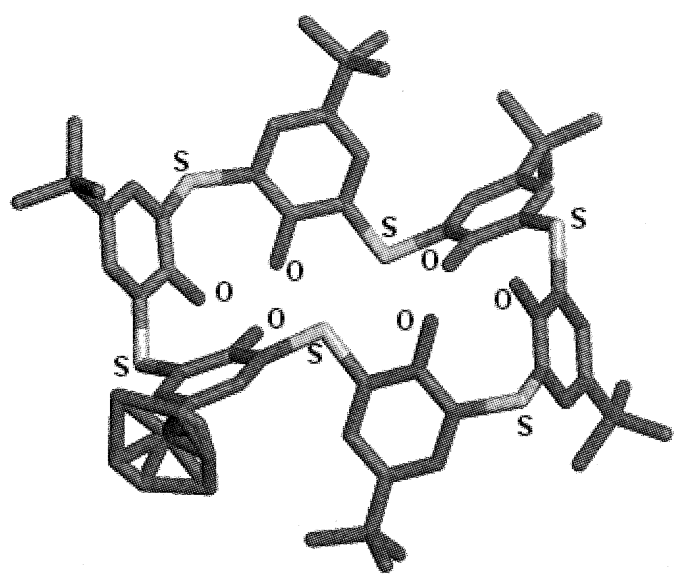

Figure 1 Crystal structure of thiacalix $[6]$ arene complex with benzyl amine. The carbons, oxygens, and sulfurs in the complex are in gray, red and yellow, respectively. All the hydrogen atoms and guest molecules are omitted for clarity. benzylamine (d) bonds with $\mathrm{NH} \cdots \mathrm{S}$ and $\mathrm{NH} \cdots \mathrm{O}$ with $3.511 \AA$ and $2.740 \AA$, respectively. It was recognized that intermolecular interaction shows $\mathrm{NH} \cdots \mathrm{N}$ distance of $2.790 \AA$ between $\mathrm{c}$ and $\mathrm{d}$ as shown in Figure 2(a) and (b). Figure 3 shows the intermolecular interaction between benzylamine and thiacalix [6] arene. Three benzylamine molecules (e, f, and g) bond with an intermolecular $\mathrm{NH} \cdots \mathrm{O}$ with $3.17,3.097$, and $3.146 \AA$, respectively. The intermolecular hydrogen bonds $\mathrm{NH}^{\cdots} \mathrm{N} \cdots \mathrm{NH}$ with 2.864 and $2.842 \AA$ among these three benzylamine were recognized. The residual benzylamine (h), which was not interacted with interlayer of thiacalix $[6]$ arene, bonded with intermolecular $\mathrm{NH} \cdots \mathrm{N}$ distance of $3.075 \AA$ with benzylamine located at next layer.

Complementary and continuous hydrogen bonds among neighboring host molecules and guests along $a$ axis afford a ladder-like polymeric 1D chain having lateral branches of tert$\mathrm{Bu}$ groups with an axial clearance of $l_{\mathrm{Bu}}=$ ca. $14.3 \AA$. Interchain hydrophobic interactions of these blanches and hydrogen bond

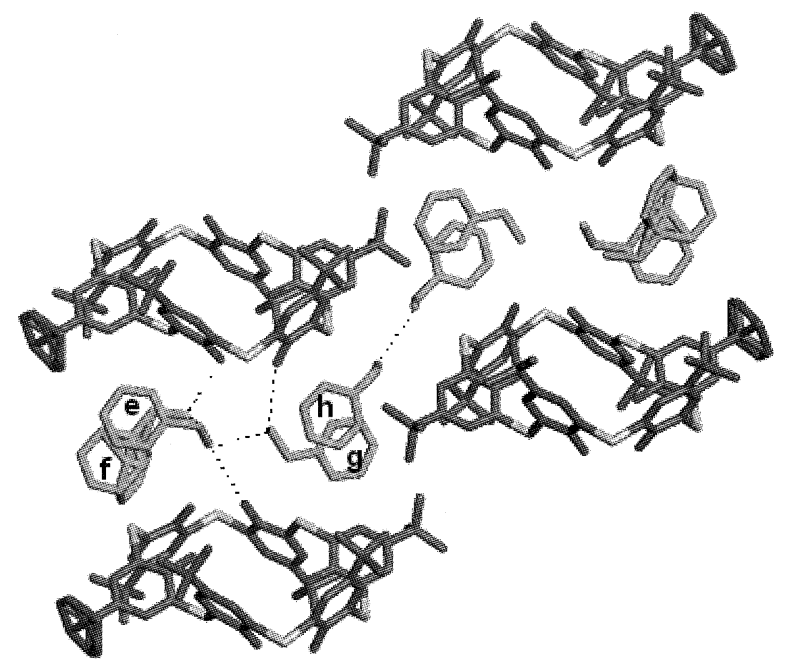

Figure 3 Locational relationship between the neighboring host molecules and outer guests (e), (f), (g) and (h). The outer guests are blue. All the inner guest molecules are omitted for clarity.
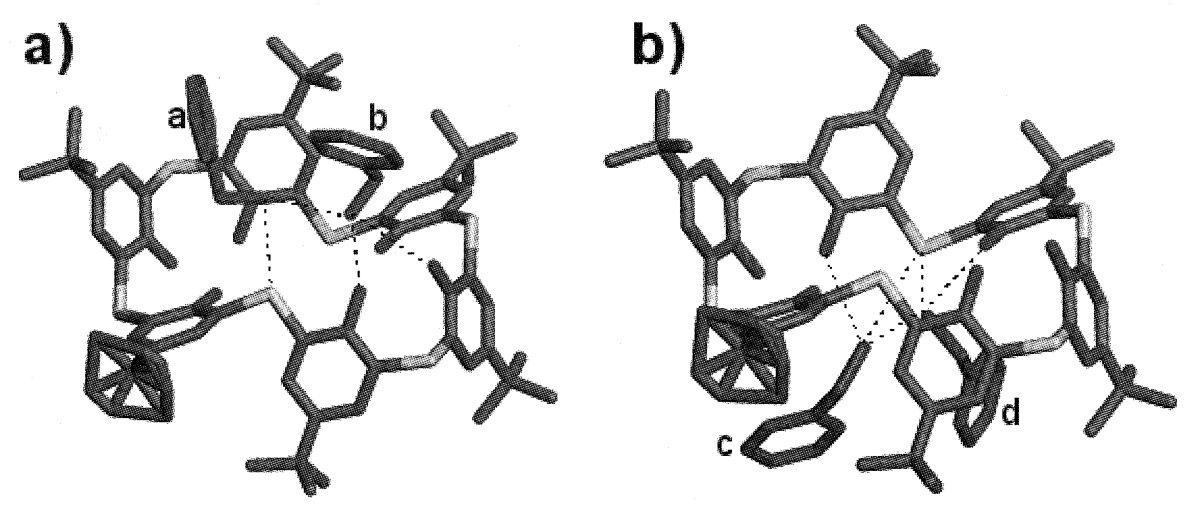

Figure 2 (a) X-ray crystal structure of thiacalix [6] arene complex with benzyl amine. The inner guests (a) and (b), are pink. Half the inner and all the outer guest molecules are omitted for clarity. (b) X-ray crystal structure of thiacalix [6] arene complex with benzyl amine. The inner guests (c) and (d), are green. Half the inner and all the outer guest molecules are omitted for clarity. 
between guest molecules (h) along the $c$ axis with a chain-tochain distance of $l_{\mathrm{c}}=\mathrm{ca} .17 .2 \AA$ and the angle with $c$ axis of $A_{\mathrm{ca}}=$ ca. $109.2^{\circ}$ give rise to a molecular sheet involving huge cavities (Figure 4). It was recognized that the crystal has a layered structure, in which ac plane is built up in a direction toward $b$ axis. The resulted cavity was not orthogonal orientated to $a c$ plane with out of alignment from $a$ and $c$ axis with ca. $133.2^{\circ}$ and ca. $129.4^{\circ}$, respectively. Each cavity is surrounded by two grooves and four tert-Bu groups; thus total four inner guests and four outer guests fill up a cavity having the widest span of $l_{\mathrm{w}}=$ ca. $16.5 \AA$. The molecular sheets in parallel with the $a c$ plane are layered in a staggered manner along the $b$ axis with the sheet distance of ca. $6.8 \AA$. Consequently the cavities in layered sheets form continuous channels with a bottleneck of $l_{\mathrm{bo}}=$ ca. 9.8 A. (Figure 5)

\section{Conclusion}

The present work suggests a potential utility of the bridging sulfur and phenol units of thiacalixarene for construction of extensively-intermolecular hydrogen bond structure in the crystalline state. To best our knowledge, it is the first example to show the intermolecular hydrogen bonding system among $-\mathrm{N} \cdots$ $\mathrm{HO},-\mathrm{S} \cdots \mathrm{HO}$, and $-\mathrm{H} \cdots \mathrm{O}$ in the calixarene chemistry.

\section{References}

1) Alexander Bilyk, Annegret K. Hall, Jack M. Harrowfield, Mir Wais Hosseni, Gilles Mislim, Brain W. Skelton, Christopher Taylor, Allan H. White, "Linear, Divergent Molecular Receptors-Subtle Effects of Transition Metal Coordination Geometry" Eur. J. Inorg. Chem., 823 (2000).

2) T. Kajiwara, N. Kon, S. Yokozawa, T. Ito, N. Iki, S. Miyano, "Synthesis, Structure, and Ferromagnetic Behavior of Decacopper(II) Cluster Complex Supported by Hexaanionic p-tert-Butylthiacalix [6] arene" J. Am. Chem. Soc., 124, 11274 (2002).

3) K. Endo, Y. Kondo, Y. Aoyama, F. Hamada, "Guest-binding properties of functionally porous crystal based on metal complex of p-tert-butylthiacalix [6] arene" Tetrahedron Lett., 44, 1355 (2003).

4) Y. Kondo, K. Endo, F. Hamada, "Potassium-Thiacalix [8] arene Assembly : Structure and Guest Sorption Profiles" Chem. Commun., 711 (2005).

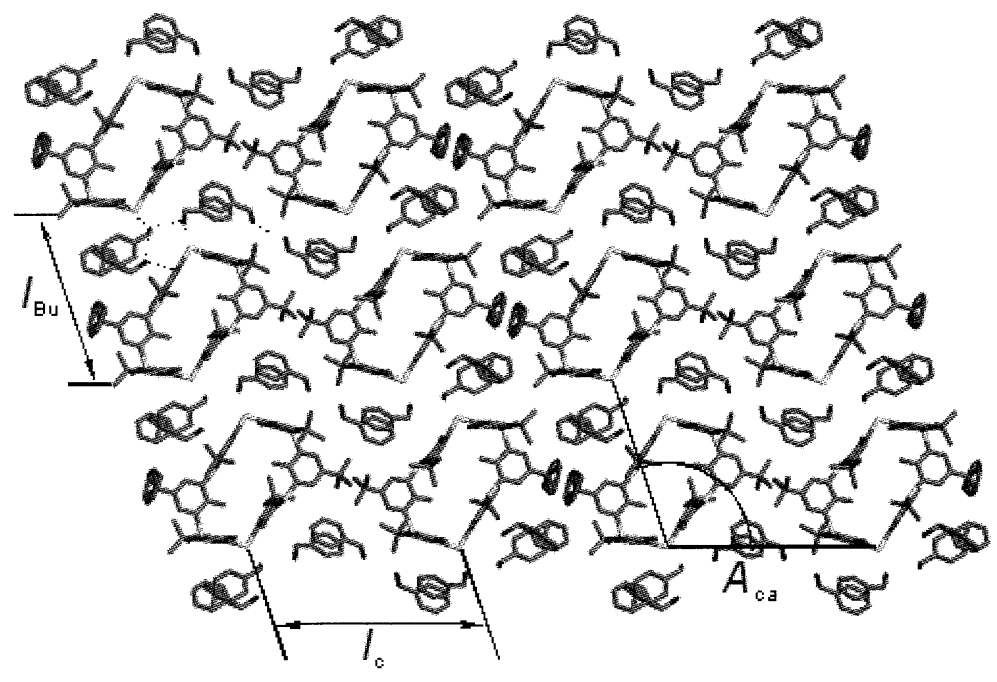

Figure 4 Structure of molecular sheet of the thiacalix $[6]$ arene complex with benzyl amine in parallel with ac plane.
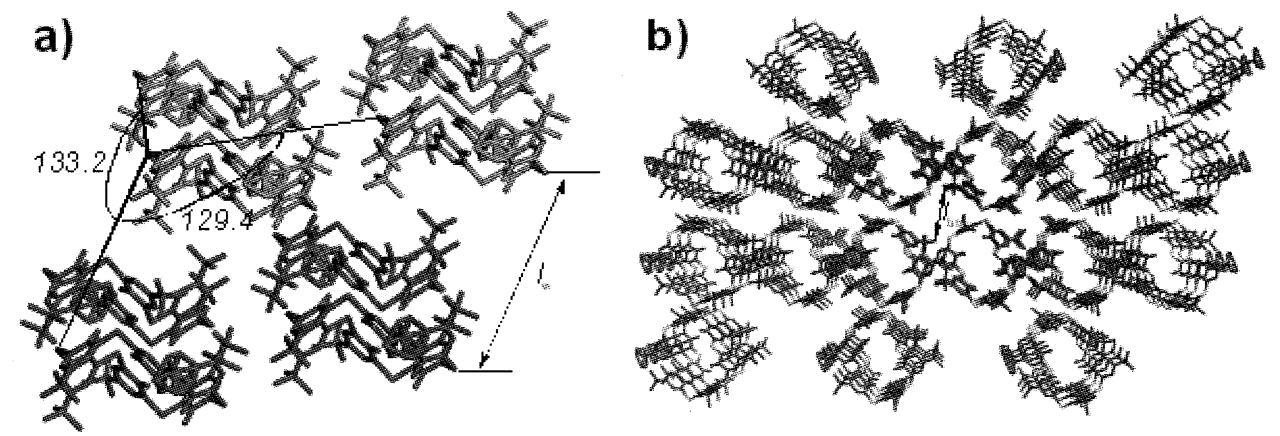

Figure 5 (a) Channel structure of thiacalix $[6]$ arene complex with benzyl amine along the $a$ axis. The first and second sheets are green and red, respectively. (b) Perspective view of channels along the $b$ axis. 
5) N. Iki, N. Morohashi, T. Suzuki, S. Ogawa, M. Aono, C. Kabuto, H. Kumagai, H. Takeya, S. Miyamori, S. Miyano, "Crystal structure and inclusion property of p-tertbutylthiacalix [6] arene" Tetrahedron Lett., 41, 2587 (2000).

6) Y. Kondo, K. Endo, N. Iki, S. Miyano, F. Hamada, "Synthesis and Crystal Structure of p-tert-butylthiacalix [8] arene: A New Member of Thiacalixarenes" J. Inclusion Phemon. 52, 45 (2005).

7) 1) Y. L. Cho, D. M. Rudkevich, A. Shivanyuk, K. Rissanen, J. Rebek, Jr., "Hydrogen-Bonding Effects in Calix [4] arene Capsules" Chem. Eur. J., 6, 3788 (2000) 2） K. S. Satheeshkumar, G. Vasu, V. Vishalakshi, M. S. Moni, R. Jayakuma, "Calix [8] arene-mediated self-assembly of tetrapeptide H-Leu-Leu-Ile-Leu-OMe" J. Mol. Recognit., 17,
67 （2004）3） A. Shivanyuk, M. Saadioui, F. Broda, I. Thondorf, M. O. Vysotsky, K. Rissaned, E. Kolehmainen, V. Bohmer, "Sterically and Guest-Controlled Self-Assembly of Calix [4] arene Derivatives" Chem. Eur. J., 10, 2138 (2004).

8) Steed J W, Atwood J L., "Supramolecular Chemistry." WileyVCH : Weinheim, (2000).

9) G. D. Andreetti, G. Calestani, F. Ugozzoli, A. Arduini, E. Ghidini, A. Pochini, R. Ungaro ; "SOLID STATE STUDIES ON p.t-BUTYL-CALIX[6]ARENE DERIVATIVES" $J$. Inclusion Phenom., 5, 123 (1987).

10） N. Iki, N. Morohashi, T. Suzuki, S. Ogawa, M. Aono, C. Kabuto, H. Kumagai, H. Takeya, S. Miyanari, S. Miyano ; "Crystal structure and inclusion property of p-tertbutylthiacalix [6] arene" Tetrahedron Lett., 41, 2587 (2000). 